\title{
ANALGESIC PROPERTIES OF SUB-ANAESTHETIC DOSES OF FLUORINATED ANAESTHETICS IN THE MOUSE
}

\author{
BY \\ M. J. NEAL AND J. M. ROBSON \\ From the Department of Pharmacology, Guy's Hospital Medical School, London, S.E.1
}

(Received August 18, 1964)

While many fluorinated compounds have been tested for anaesthetic properties in animals, little or no attention has been paid to the analgesic action that these compounds may possess when administered in subanaesthetic doses. The anaesthetic action of pentafluorobenzene, pentafluorobromobenzene and hexafluorobenzene has been described by Burns, Hall, Bracken \& Gouldstone $(1961,1964)$.

Sulphur hexafluoride is capable of producing loss of consciousness in premedicated subjects (Virtue \& Weaver, 1952), but Lester \& Greenberg (1950) and Specht \& Brubach (1951) found that it was inert in rats. Methoxyflurane (2,2-dichloro-1,1-difluoro-1-methoxyethane) was first described by Poznak \& Artusio (1960) and the analgesic properties of this drug in man have been investigated by Dundee \& Love (1963).

To the best of our knowledge no work has been published on the anaesthetic action of 1,2,3,4-tetrafluorobenzene. In the present paper the results obtained in testing these compounds for analgesic action in mice are described.

\section{METHODS}

Estimation of analgesia. With the exception of sulphur hexafluoride, the compounds were tested for analgesic activity using the method and apparatus previously described (Neal \& Robson, 1964a). The anaesthetic drugs were administered with oxygen as the only other gas, unless otherwise stated. The concentrations of anaesthetic and nitrous oxide are expressed as percentages $\mathrm{v} / \mathrm{v}$.

Sulphur hexafluoride. The method of estimating analgesia was identical to that used for the other compounds but, because of the high cost of this gas, a closed circuit was used after the first 5 min of each experiment. The circuit (Fig. 1) consisted of gas chamber, gas reservoir (10-1. aspirator), glass tube ( $1 \times 10 \mathrm{in}$.) containing soda-lime, flowmeter (2-1./min oxygen rotameter), and a circulating pump. Two taps could be operated to enable a continuous flow of gas mixture to be flushed through most of the circuit. A rotameter calibrated for sulphur hexafluoride and connected in parallel with oxygen and nitrous oxide rotameters was used to obtain the required mixture for continuous flow. This was used for the first $5 \mathrm{~min}$ of each experiment to flush out the air contained in the gas chamber. For the remaining part of the experiment the closed circuit was used. The gas reservoir, which was calibrated in litres, was filled with water and the required gas mixture was obtained by running water out from the bottom of the aspirator, the appropriate gas being drawn in at the top. As each gas was drawn into the reservoir separately, about 15 min were allowed for mixing by diffusion.

Estimation of anaesthesia. Mice were judged to be anaesthetized when they did not right themselves on electrical stimulation. 


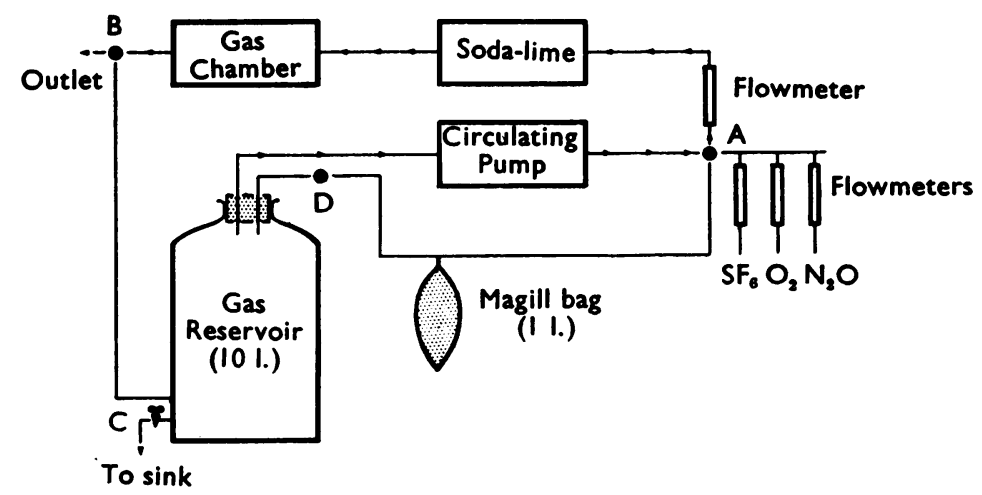

Fig. 1. Closed circuit used for sulphur hexafluoride experiments. The reservoir was filled with gas by emptying water through tap C. Gas was drawn in from the Magill bag which was kept inflated by admitting the anaesthetics via tap A from the gas cylinders. When the reservoir was filled, tap D was closed and tap A operated to connect the flowmeters to the gas chamber. The required mixture was then passed through the chamber for $5 \mathrm{~min}$; then taps $A$ and $B$ were operated to close the circuit and the circulating pump was started.

Statistical methods. The methods used to assess the significance of the analgesic effect of drugs have been described previously (Neal \& Robson, 1964a). To determine whether or not nitrous oxide significantly increased the anaesthetic action of a drug, the probability $(P)$ was calculated as described by Bailey (1959).

Drugs used. These were hexafluorobenzene, pentafluorobenzene, 1,2,3,4-tetrafluorobenzene, pentafluorobromobenzene (Imperial Smelting), sulphur hexafluoride (I.C.I.) and methoxyflurane (2,2-dichloro1,1-difluoro-1-methoxyethane; Penthrane, Abbott). The aromatic compounds were stated by Imperial Smelting to be not less than $99 \%$ pure. Sulphur hexafluoride was supplied by I.C.I. as a very pure gas; possible impurities being sulphur tetrafluoride 20 p.p.m., disulphur hexafluoride less than 1 p.p.m., and water 15 p.p.m. The methoxyflurane contained $0.01 \% \mathrm{w} / \mathrm{w}$ butylated hydroxytoluene; it was stated to be $99.9 \%$ pure.

\section{RESULTS}

A summary of some results is given diagrammatically in Fig. 2.

Hexafluorobenzene. In a concentration of $1 \%$, this produced a slight but definite analgesic effect (Fig. 2), which became significant after $40 \mathrm{~min}(P<0.02)$; at this time, 14\% of the mice had been anaesthetized. Increasing the concentration to $1.6 \%$ rapidly produced anaesthesia in all mice without the development of significant analgesia.

Hexafluorobenzene with nitrous oxide. The addition of $40 \%$ nitrous oxide significantly increased the analgesic action of $1 \%$ hexafluorobenzene (Fig. 2$)(P<0.02$ at $5 \mathrm{~min})$; the anaesthetic action was significantly potentiated at $40 \mathrm{~min}$ and after $50 \mathrm{~min}$ all the mice had lost consciousness. Nitrous oxide, $80 \%$, markedly potentiated the anaesthetic action of $1 \%$ hexafluorobenzene, all the mice being anaesthetized within $30 \mathrm{~min}$. This combination produced only a slight analgesic effect before the mice lost consciousness.

Pentafluorobenzene. In a concentration of $0.5 \%$ this produced an analgesic effect which was similar to that produced by $1 \%$ hexafluorobenzene (Fig. 2). Increasing the concentration to $1 \%$ produced anaesthesia in all mice within 30 min, significant analgesia being produced before the mice became unconscious. Thus pentafluorobenzene seems to be a slightly more 


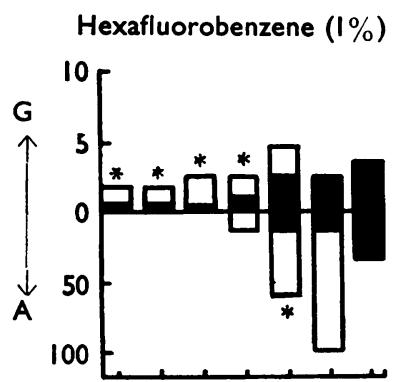

Sulphur hexafluoride $(90 \%)$

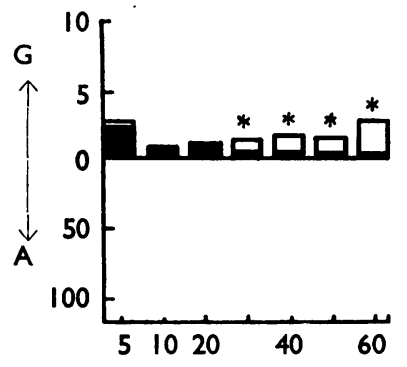

Tetrafluorobenzene $(0.5 \%)$

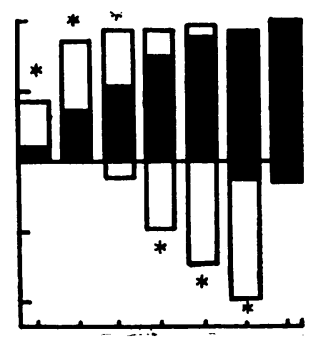

Methoxyflurane $(0.35 \%)$

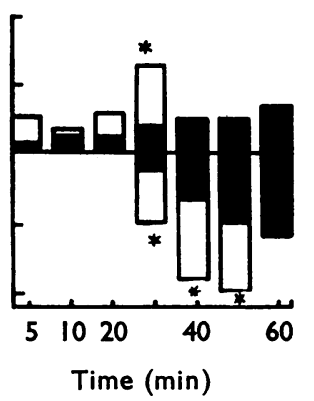

Pentafluorobenzene $(0.5 \%)$

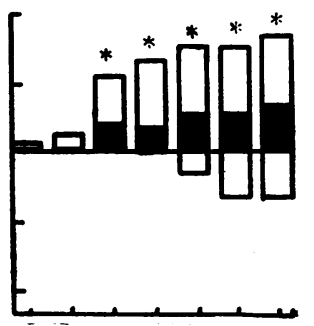

Halothane $(0.75 \%)$

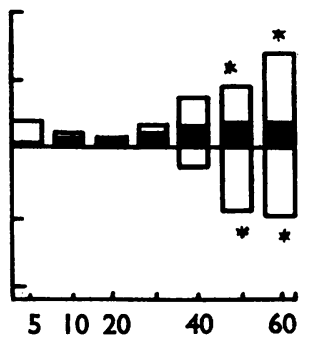

Fig. 2. The analgesic and anaesthetic effects of the drugs tested (except pentafluorobromobenzene), and the effect of nitrous oxide on these actions. $G$ is the analgesic effect (mean negative response), the maximum score being 10. A is the percentage of mice anaesthetized. Time from the beginning of drug administration in minutes along the abscissa. Filled columns show effects of drug alone. Empty columns show effects of mixture of drug and nitrous oxide. In both instances oxygen was added to $100 \%$. Above the zero line indicates that the analgesic effect of the drug is significantly potentiated by nitrous oxide $(P<0.05) ; *$ below the zero line indicates that the anaesthetic effect of drug is significantly potentiated by nitrous oxide $(P<0.05)$.

potent anaesthetic than hexafluorobenzene, the latter compound in a concentration of $1 \%$ producing anaesthesia in only $14 \%$ of mice after $40 \mathrm{~min}$.

Pentafluorobenzene with nitrous oxide. Nitrous oxide, $50 \%$, markedly potentiated the analgesic action of $0.5 \%$ pentafluorobenzene (Fig. 2). While some anaesthetic action became evident with this mixture $(33 \%$ mice being anaesthetized at $60 \mathrm{~min}$ as opposed to none anaesthetized by pentafluorobenzene alone), this increase in anaesthetic effect was not significant $(P=0.07$ at $50 \mathrm{~min})$. The large potentiation of analgesic effect with a much smaller effect on anaesthetic action was very similar to that obtained previously with halothane (Neal \& Robson, 1964b). The results obtained with halothane are included in Fig. 2 for comparison.

1,2,3,4-Tetrafluorobenzene. The effect of tetrafluorobenzene, $0.5 \%$, is shown in Figs. 2 and 3 . In a concentration of $0.5 \%$ this compound, produced excellent analgesia, no mice being anaesthetized at $40 \mathrm{~min}$. After $30 \mathrm{~min}$ the analgesic effect was approximately the same as that produced by methadone hydrochloride, $8 \mathrm{mg} / \mathrm{kg}$, injected intraperitoneally. Tetrafluorobenzene, $0.75 \%$, again produced excellent analgesia (Fig. 3), but after $30 \mathrm{~min}$ 


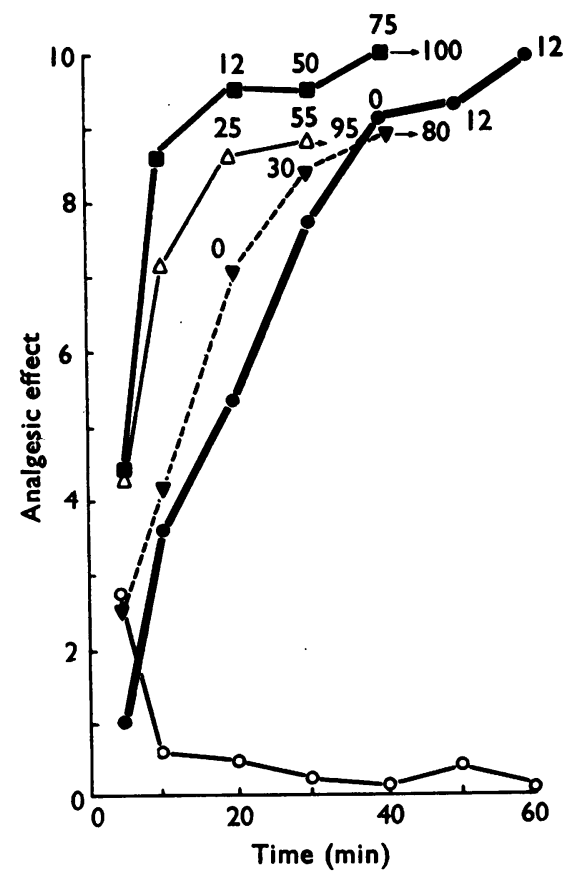

Fig. 3. The analgesic effect of tetrafluorobenzene $1 \%$ after $10 \mathrm{~min}$ is atout the same as that produced by $8 \mathrm{mg} / \mathrm{kg}$ of methadone hydrochloride intraperitoneally. Concentrations of $0.75 \%$ and $0.5 \%$ tetrafluorobenzene produce approximately the same degree of analgesia as $1 \%$ tetrafluorobenzene, but the equivalent effect develops more slowly. The lower concentrations of tetrafluorobenzene produce anaesthesia in a smaller proportion of mice. Thus, while $1 \%$ tetrafluorobenzene anaesthetizes $55 \%$ of mice at $30 \mathrm{~min}, \mathbf{0 . 5 \%}$ tetrafluorobenzene anaesthetizes no mice at this time. However, $50 \%$ nitrous oxide potentiates the anaesthetic action of $0.5 \%$ tetrafluorobenzene and at $30 \mathrm{~min} 50 \%$ of mice lose consciousness. Nitrous oxide also significantly potentiates the analgesic action of $0.5 \%$ tetrafluorobenzene. Figures on graph indicate percentage of mice anaesthetized. $\Delta$ Tetrafluorobenzene, $1 \%$; $\nabla$ tetrafluorobenzene, $0.75 \%$; tetrafluorobenzene, $0.5 \%$; tetrafluorobenzene, $0.5 \%+50 \%$ nitrous oxide; and $\bigcirc$ control.

$30 \%$ of the mice had lost consciousness. Increasing the concentration to $1 \%$ produced an analgesic effect within $10 \mathrm{~min}$, which was roughly equivalent to that produced by $8 \mathrm{mg} / \mathrm{kg}$ of methadone hydrochloride injected intraperitoneally; at this time no mice had been anaesthetized, but after $30 \mathrm{~min}$ over $50 \%$ of the mice lost consciousness. This compound was the most potent inhalation analgesic so far tested. Unfortunately about half of the mice exposed to tetrafluorobenzene died in the postanaesthetic period; because of this some mice which survived $24 \mathrm{hr}$ after being exposed to $1 \%$ tetrafluorobenzene were killed, and their hearts, liver, kidneys and lungs were examined histologically. All the mice examined showed fresh hepatic parenchymal coagulative necrosis, which was very variable in degree. In two out of three mice mild renal tubular necrosis had also occurred. No abnormalities were found in the heart or lungs. Thus tetrafluorobenzene was hepatotoxic and not considered suitable for further investigation.

Tetrafluorobenzene with nitrous oxide. Nitrous oxide, $50 \%$, greatly potentiated the analgesic and anaesthetic actions of $0.5 \%$ tetrafluorobenzene (Figs. 2 and 3). Initially nitrous 
oxide affected only the analgesic action of tetrafluorobenzene; thus at $10 \mathrm{~min}$ the analgesic effect was more than double that produced by tetrafluorobenzene alone while no mice were anaesthetized. However, by $50 \mathrm{~min}$ the mixture of nitrous oxide and tetrafluorobenzene had anaesthetized all the mice, while $0.5 \%$ tetrafluorobenzene alone caused loss of consciousness in only $12 \%$ of mice. Although at 30 and 40 min nitrous oxide appeared to cause relatively little increase in the analgesic effect of tetrafluorobenzene, this was probably due to the fact that the mean negative responses were becoming progressively nearer to the maximum possible score for analgesia (10).

Pentafluorobromobenzene. This was an interesting compound in that different concentrations $(0.5$ to $2 \%$ ) produced almost identical results. At $20 \mathrm{~min}, 2,1$ and $0.5 \%$ produced anaesthesia in 17,10 and $12 \%$ of mice respectively; at this time there was no significant difference between the analgesic effects produced by these different concentrations. Mice anaesthetized with this compound recovered rather slowly, but all survived.

Methoxyflurane. In a concentration of $0.35 \%$, this produced slight but definite analgesia which became significant at $30 \mathrm{~min}(P<0.02)$ (Fig. 2). This concentration anaesthetized $11 \%$ of the mice after $30 \mathrm{~min}$ and $61 \%$ after $60 \mathrm{~min}$. The analgesic effect produced by $0.35 \%$ methoxyflurane was not significantly different from that obtained previously with halothane, $0.75 \%$ (Neal \& Robson, 1964b). Increasing the concentration of methoxyflurane to $0.5 \%$ caused loss of consciousness in $50 \%$ of mice within $30 \mathrm{~min}$, although the analgesia produced at this time was not greater than that produced by $0.35 \%$ methoxyflurane.

Methoxyflurane with nitrous oxide. Although $25 \%$ nitrous oxide significantly increased the analgesic action of $0.35 \%$ methoxyflurane $(P<0.01$ at $30 \mathrm{~min})$ (Fig. 2), the effect was weak, and the main effect of nitrous oxide was to potentiate markedly the anaesthetic action of methoxyflurane; $90 \%$ of mice were anaesthetized at $40 \mathrm{~min}$ compared to $33 \%$ of mice treated with methoxyflurane alone. This potentiation of anaesthetic action was even more strikingly shown by mixing $50 \%$ nitrous oxide with $0.35 \%$ methoxyflurane. This combination produced anaesthesia in $90 \%$ of mice within 20 min without the development of any significant analgesia.

Sulphur hexafluoride. In concentrations up to $90 \%$ this produced no anaesthesia or analgesic effect within $1 \mathrm{hr}$.

Sulphur hexafluoride with nitrous oxide. Preliminary experiments using different proportions of sulphur hexafluoride and nitrous oxide suggested that the most effective combination consisted of equal proportions of these two gases, with just enough oxygen to prevent anoxia. Sulphur hexafluoride, $45 \%$, with nitrous oxide, $45 \%$, did not produce anaesthesia in any mice, but a significant analgesic effect was produced after $30 \mathrm{~min}$ (Fig. 2) $(P<0.001)$. This effect remained significant for the duration of the experiment $(P<0.05$ at $60 \mathrm{~min})$.

\section{DISCUSSION}

Apart from lack of toxicity, two factors must be considered in assessing inhalation analgesic agents for possible clinical use: the actual degree of analgesia produced within a reasonable time, and the anaesthetic potency of the drug.

Ideally the concentration required to produce analgesia should not cause anaesthesia, even after prolonged inhalation. In practice it is difficult to produce good analgesia $i$ 
mice without subsequent loss of consciousness in at least a proportion of animals tested. Of the compounds investigated, only tetrafluorobenzene in a concentration of $0.5 \%$ approached the ideal. Analgesia was produced quite rapidly and no mice were anaesthetized within $40 \mathrm{~min}$. Unfortunately this compound was toxic and killed about half of the mice exposed to it. Although this drug was not considered suitable for further investigation, the results do show that it is possible to obtain good analgesia by the use of an inhalation agent given in subanaesthetic doses. The remainder of the aromatic compounds tested did not produce much analgesia without a considerable proportion of the mice being anaesthetized.

Pentafluorobenzene produced an analgesic effect which was similar to that produced by halothane (Neal \& Robson, 1964b). The effect of nitrous oxide on the action of these compounds was also similar (Fig. 2). In both cases the analgesic rather than the anaesthetic action was potentiated. In contrast, the effect of nitrous oxide on the other compounds tested, hexafluorobenzene, tetrafluorobenzene and methoxyflurane, was to potentiate mainly the anaesthetic action, although with all these drugs the analgesic action was also significantly increased at some time during the experiment.

Because of its similarity in action to halothane, pentafluorobenzene would have been worth further investigation for possible use as an anaesthetic agent, but unfortunately this compound is inflammable in oxygen.

The similarity of effect caused by different concentrations of pentafluorobromobenzene suggests that there is some factor limiting the uptake of this compound. Because of the slow recovery from this drug it is not considered suitable for further investigation. It is interesting that nitrous oxide potentiates the analgesic action of sulphur hexafluoride. It was hoped that a mixture of sulphur hexafluoride and nitrous oxide would produce anaesthesia in mice, but unfortunately this did not occur. The effect of mixtures of sulphur hexafluoride and nitrous oxide in other species is at present being investigated.

Methoxyflurane was the only compound tested which is used clinically in man. It is widely stated that this anaesthetic produces very good analgesia and it has been used for this purpose in obstetrics. Using a concentration of $0.42 \%$, Romagnoli \& Korman (1962) found that methoxyflurane produced a " haze of consciousness and analgesia." These clinical impressions of the analgesic action of methoxyflurane were not confirmed in mice. Although $0.35 \%$ methoxyflurane produced a significant analgesic effect, this was only slight, and was not significantly greater than the analgesic effect produced by $0.75 \%$ halothane (Neal \& Robson, 1964b), though it is generally considered that halothane produces no analgesia in man.

The absence of an analgesic action of methoxyflurane in subanaesthetic doses has also been demonstrated in man, using a tibial pressure method of analgesimetry (Dundee \& Love, 1963). Thus, the results obtained using different experimental pain techniques in mice and man agree quite well, but disagree with clinical impressions. This is difficult to explain, but may be due to the fact that clinically methoxyflurane is usually used together with nitrous oxide. These two drugs when used together may produce an analgesic effect which is greater than that produced by either anaesthetic alone. This suggestion is partially supported by the finding that in mice nitrous oxide significantly potentiates the analgesic action of methoxyflurane. 


\section{SUMMARY}

1. The analgesic action of subanaesthetic doses of six fluorinated compounds was investigated in mice, the drugs being given by inhalation. These were hexafluorobenzene, pentafluorobenzene, 1,2,3,4-tetrafluorobenzene, pentafluorobromobenzene, methoxyflurane and sulphur hexafluoride.

2. The analgesic effect of the compounds was estimated by an electrical method in which shocks were administered to mice through electrodes attached to their tails.

3. With the exception of sulphur hexafluoride all the drugs were capable of producing anaesthesia and all produced some degree of analgesia.

4. Hexafluorobenzene $(1 \%)$, pentafluorobenzene $(0.5 \%)$, pentafluorobromobenzene $(0.5 \%)$ and methoxyflurane $(0.35 \%)$ produced only slight analgesia; tetrafluorobenzene produced excellent analgesia but was unfortunately hepatotoxic.

5. Nitrous oxide significantly potentiated the analgesic action of all the drugs tested. With the exception of sulphur hexafluoride and pentafluorobenzene the anaesthetic action of these compounds was also potentiated.

6. The excellent analgesic action of tetrafluorobenzene shows that it is possible to obtain good analgesia by the use of an inhalation agent given in subanaesthetic doses, and encourages the hope that a similar nontoxic compound may be discovered.

We are grateful to the Medical Research Council for a personal grant (to M.J.N.) and for a grant for expenses; also to Abbotts Ltd. for a gift of methoxyflurane (Penthrane). We would like to thank Dr G. A. K. Missen of Guy's Hospital Medical School for his advice on the pathological changes produced by tetrafluorobenzene. We are also grateful to Imperial Smelting Ltd. (Avonmouth) for supplying the polyfluorinated aromatic compounds.

\section{REFERENCES}

BaILEY, N. T. J. (1959). Statistical Methods in Biology, p. 63. London: English Universities.

Burns, T. H. S., HALI, J. M., BrackeN, A. \& Gouldstone, G. (1961). An investigation of new fluorine compounds in anaesthesia (3). The anaesthetic properties of hexafluorobenzene. Anaesthesia, 16, 333-339.

BurNs, T. H. S., Hall, J. M., Bracken, A. \& Gouldstone, G. (1964). Fluorine compounds in anaesthesia (6). Examination of fourteen heavily halogenated ring compounds. Anaesthesia, 19, 167-176.

DUNDEE, J. W. \& LOVE, W. J. (1963). Alterations in response to somatic pain associated with anaesthesia. XIV: effects of subnarcotic concentrations of methoxyflurane. Brit.J. Araesth., 35, 301-3C4.

LesTER, D. \& GREENBERG, L. A. (1950). The toxicity of sulphur hexafluoride. Arch. industr. Hyg., 2, 348-349.

NeAL, M. J. \& Robson, J. M. (1964a). The measurement of analgesic properties of inhalation drugs given in subanaesthetic concentrations. Brit. J. Pharmacol., 22, 590-596.

NeAl, M. J. \& Robson, J. M. (1964b). The analgesic properties of subanaesthetic doses of anaesthetics in the mouse. Brit.J. Pharmacol., 22, 596-603.

PozNAK, A. V. \& Artusio, J. F. (1960). Anesthetic properties of a series of fluorinated compounds. II. Fluorinated ethers. Toxicol.oppl. Pharmacol., 2, 374-378.

Romagnoli, A. \& Korman, D. (1962). Methoxyflurane in obstetrical anesthesia and analgesia. Canad. Anesth. Soc. J., 9, 414-418.

SPECHT, H. \& BRUBACH, H. F. (1951). Inhalation of sulphur hexafluoride. Science, 114, 662-663.

VIRTUE, R. W. \& WEAVER, R. H. (1952). Anaesthetic properties of sulphur hexafluoride. Anaesthesiology, 13, 605-607. 